\title{
Structural Refinement of the Tubulin Ligand (+)-Discodermolide to Attenuate Chemotherapy-Mediated Senescence ${ }^{\circledR}$
}

\author{
Boying Guo, Alicia Rodriguez-Gabin, Andrea E. Prota, Tobias Mühlethaler, Nan Zhang, \\ Kenny Ye, Michel O. Steinmetz, Susan Band Horwitz, Amos B. Smith, III, \\ and Hayley M. McDaid
}

Department of Chemistry, Monell Chemical Senses Center and Laboratory for Research on the Structure of Matter, University of Pennsylvania, Philadelphia, Pennsylvania (B.G., N.Z., A.B.S.); Departments of Molecular Pharmacology (A.R.-G., S.B.H., H.M.M.), Epidemiology (K.Y.), and Medicine (H.M.M.), Albert Einstein College of Medicine, Bronx, New York; Laboratory of Biomolecular Research, Division of Biology and Chemistry, Paul Scherrer Institut, Villigen, Switzerland (A.E.P., T.M., M.O.S.); and University of Basel, Biozentrum, Basel, Switzerland (M.O.S.)

Received July 8, 2019; accepted May 13, 2020

\begin{abstract}
The natural product (+)-discodermolide (DDM) is a microtubule stabilizing agent and potent inducer of senescence. We refined the structure of DDM and evaluated the activity of novel congeners in triple negative breast and ovarian cancers, malignancies that typically succumb to taxane resistance. Previous structure-activity analyses identified the lactone and diene as moieties conferring anticancer activity, thus identifying priorities for the structural refinement studies described herein. Congeners possessing the monodiene with a simplified lactone had superior anticancer efficacy relative to taxol, particularly in resistant models. Specifically, one of these congeners, B2, demonstrated 1) improved pharmacologic properties, specifically increased maximum response achievable and area under the curve, and decreased $\mathrm{EC}_{50}$; 2) a uniform dose-response profile across genetically heterogeneous cancer cell lines relative to taxol or DDM; 3) reduced propensity for senescence induction relative to DDM; 4) superior long-term activity in cancer cells versus taxol or DDM; and 5) attenuation of metastatic characteristics in treated cancer cells. To contrast the binding of B2 versus
\end{abstract}

DDM in tubulin, $\mathrm{X}$-ray crystallography studies revealed a shift in the position of the lactone ring associated with removal of the C2-methyl and C3-hydroxyl. Thus, B2 may be more adaptable to changes in the taxane site relative to DDM that could account for its favorable properties. In conclusion, we have identified a DDM congener with broad range anticancer efficacy that also has decreased risk of inducing chemotherapy-mediated senescence.

\section{SIGNIFICANCE STATEMENT}

Here, we describe the anticancer activity of novel congeners of the tubulin-polymerizing molecule (+)-discodermolide. A lead molecule is identified that exhibits an improved dose-response profile in taxane-sensitive and taxane-resistant cancer cell models, diminished risk of chemotherapy-mediated senescence, and suppression of tumor cell invasion endpoints. X-ray crystallography studies identify subtle changes in the pose of binding to $\beta$-tubulin that could account for the improved anticancer activity. These findings support continued preclinical development of discodermolide, particularly in the chemorefractory setting.

\section{Introduction}

(+)-Discodermolide (DDM; Fig. 1A) is a potent inducer of tubulin polymerization that has been evaluated as a chemotherapeutic in the taxane-refractory setting. However, despite its promise as anticancer molecule, DDM caused serious

This work was supported by National Cancer Institute [Grant CA077263], the Breast Cancer Research Foundation, the National Foundation for Cancer Research, and the Swiss National Science Foundation [Grant 31003A_166608] (MOS). Research reported in this publication was also supported by the Albert Einstein Cancer Center Support Grant of the National Institutes of Health [Grant P30CA013330]. The content is solely the responsibility of the authors and does not necessarily represent the official views of the National Institutes of Health.

https://doi.org/10.1124/mol.119.117457.

S This article has supplemental material available at molpharm. aspetjournals.org. interstitial pneumopathy in clinical evaluation (Mita et al., 2004), a condition typically associated with fibrosis and senescence (Jones, 2018). We previously characterized DDM as a potent inducer of chemotherapy-induced senescence (CIS) (Klein et al., 2005; Chao et al., 2011; Nadaradjane et al., 2018), defined as prolonged exit from proliferation that is distinct from quiescence.

It is widely accepted that anticancer therapies induce senescence to varying degrees (Ewald et al., 2010). CIS has been shown to be a causative factor in bleomycin-associated pulmonary toxicity (Aoshiba et al., 2013; Schafer et al., 2017) and doxorubicin-mediated cardiac toxicity and systemic inflammation (Demaria et al., 2017). Furthermore, toxicities from cancer therapy can prevent the completion of a prescribed

ABBREVIATIONS: AUC, area under the curve; CIS, chemotherapy-induced senescence; DDM, discodermolide; $\mathrm{E}_{\mathrm{Max}}$, maximum response achievable; EMT, epithelial to mesenchymal transition; MTS, 3-(4,5-dimethylthiazol-2-yl)-5-(3-carboxymethoxyphenyl)-2-(4-sulfophenyl)-2Htetrazolium; ROS, reactive oxygen species; SA- $\beta$-gal, senescence-associated $\beta$-galactosidase; SASP, senescence-associated secretory phenotype; SRB, sulforhodamine B; TNBC, triple-negative breast cancer. 
A

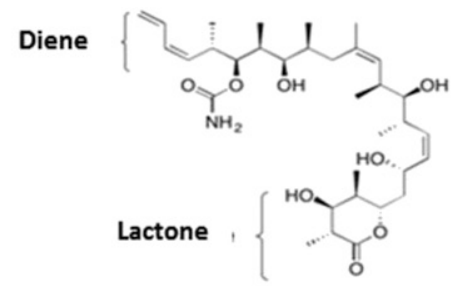

(+)- Discodermolide (DDM)

B

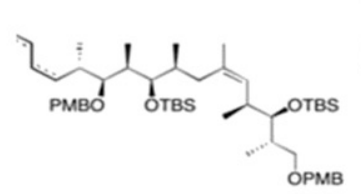

D1-3

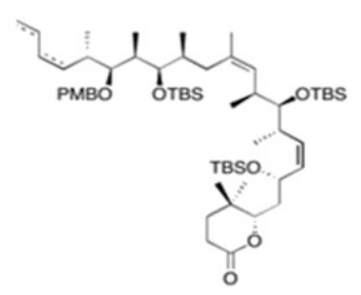

F1-3
1). $\mathrm{BCl}_{3}$;

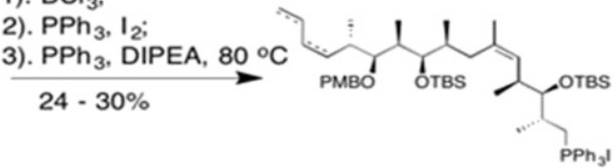

E1-3

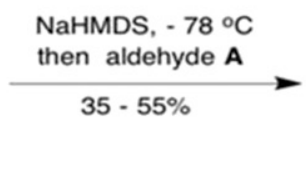

aldehyde $A$

$35 \cdot 55 \%$

1) $\mathrm{DDQ}$;

2) $\mathrm{CCl}_{3} \mathrm{CONCO}$ 3) $4 \mathrm{~N} \mathrm{HCl}, \mathrm{MeOH}$
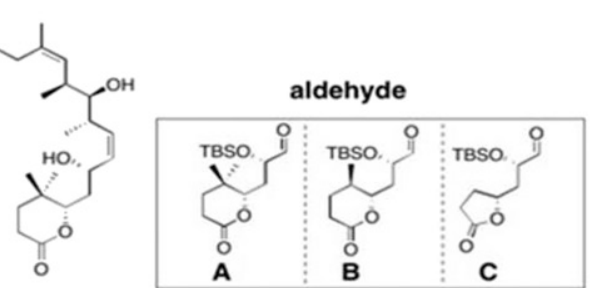

A1-3

\section{C}

$\begin{array}{lll}\text { Diene } & \text { Mono }\end{array}$

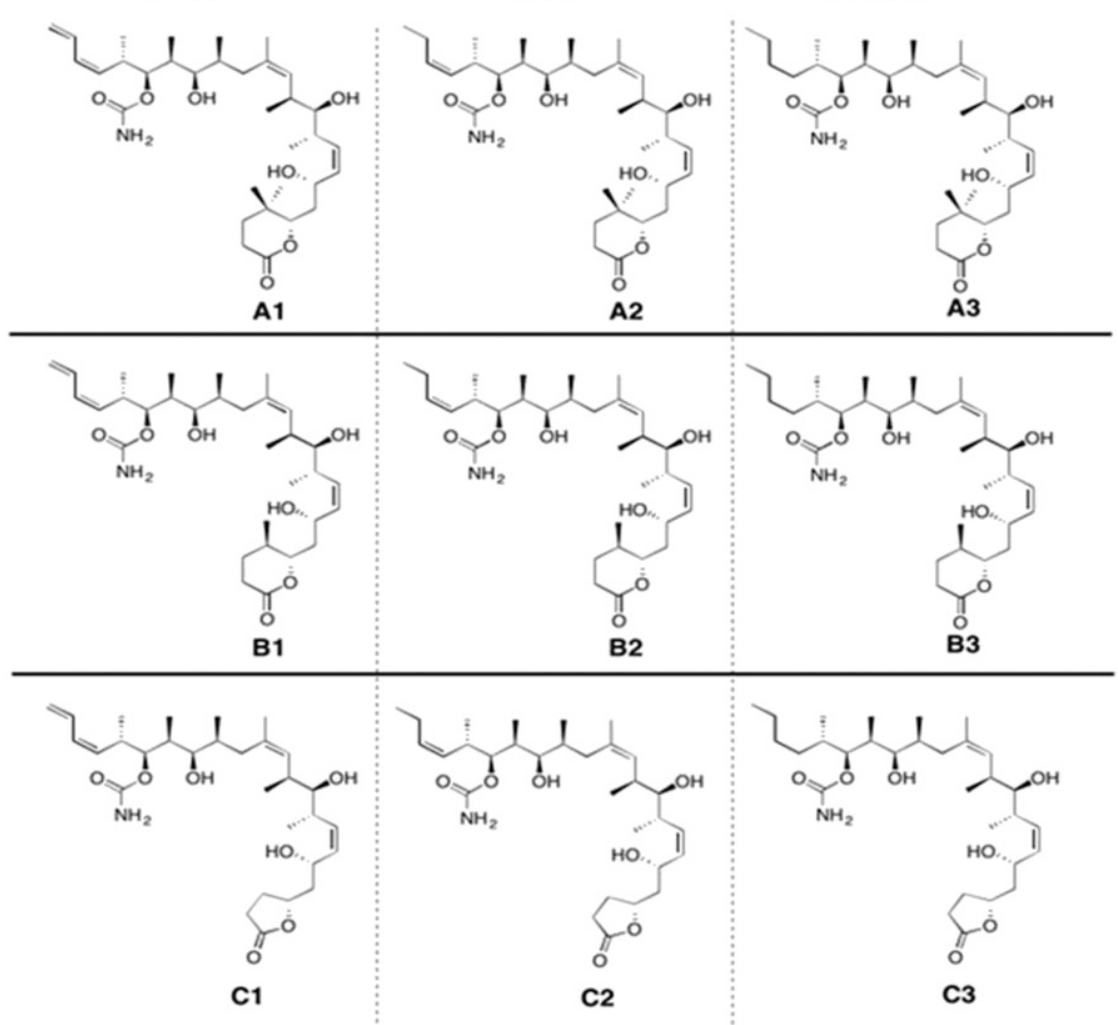

Fig. 1. Structure of (+)-DDM-modified congeners. (A) Chemical structure of (+)-DDM illustrating the lactone and diene moieties. (B) Representative synthesis of DDM analogs. (C) Structures of the congener series (A1-C3) available for biologic analysis.

course of treatment or thwart extended treatment. Aside from the collateral damage that CIS causes in nontransformed cells (Childs et al., 2015), tumor cells can also become senescent, thereby evading the cell cycle-dependent action of many chemotherapeutic drugs (Samaraweera et al., 2012). These cells then become a source of chronic inflammation via the 
senescence-associated secretory phenotype (SASP), which can accelerate disease progression via multiple effects on the tumor microenvironment (Laberge et al., 2012). Finally, senescent cancer cells can resume proliferation, giving rise to more tumorigenic progeny (Gosselin et al., 2009; Chao et al., 2011; Milanovic et al., 2018). Therapy-induced aneuploidization leading to replication stress and DNA damage signaling is a known driver of CIS (Santaguida et al., 2017; Watson and Elledge, 2017). Based on our experience with DDM both in vitro and in vivo, coupled with increased awareness that CIS can mediate the toxic effects of chemotherapy, we hypothesized that DDM-mediated senescence may have contributed to its toxicity in patients.

Taxol, unlike DDM, is a comparatively weak inducer of CIS (Klein et al., 2005; Nadaradjane et al., 2018). This is hypothesized to be due to variation in the affinity and pose of binding in the taxol-binding domain of tubulin (Prota et al., 2017), or binding of tubulin ligands to specific tubulin isotypes, or downstream effects thereof. Prior studies of DDM structureactivity relationships identified the lactone and diene moieties as regions for further modification that yielded congeners with superior anticancer activity (Smith et al., 2005, 2011; Smith and Freeze, 2007; Shaw, 2008). For example, C(1)-C(5) simplified lactone congeners were demonstrated to have superior anticancer activity in cancer cell lines (Shaw et al., 2005; Smith and Xian, 2005). Coincidentally, DDM is differentially metabolized by oxidation of $\mathrm{C}(4)-\mathrm{C}(5)$ of the lactone and epoxidation of $\mathrm{C}(21)-\mathrm{C}(22)$ or $\mathrm{C}(23)-\mathrm{C}(24)$ diene (Fan et al., 2009). These observations led us to hypothesize that lactone and diene modifications could stabilize against oxidative metabolism and potentially influence anticancer activity. Building upon the original potential of DDM in the taxanerefractory setting, we set out to refine its chemical structure further.

We favored a multiparameter analysis approach (FallahiSichani et al., 2013) to analyze the activity of these novel congeners. The most commonly used metric to describe preclinical activity is potency, or $\mathrm{EC}_{50}$ (the concentration at the half-maximal effect). However, potency typically describes doses associated with proliferative arrest rather than tumor cell death. Importantly, failure to consider other features of the dose-response relationship, such as maximum response achievable ( $\mathrm{E}_{\mathrm{Max}}$; efficacy), and area under the curve (AUC; potency and efficacy in a single measure) increases the probability of selecting molecules that are strong inducers of CIS. Thus, lead DDM congeners were identified on the basis of superior pharmacologic profiles (combined use of $\mathrm{E}_{\mathrm{Max}}$, AUC, and $\mathrm{EC}_{50}$ ) relative to DDM or taxol, coupled with propensity to induce CIS, a cell fate that is largely ignored in drug development. Collectively, our data establish novel congeners of DDM as promising therapeutics for potential use in the chemorefractory setting.

\section{Materials and Methods}

Synthesis of Simplified DDM Congeners and X-Ray Crystallography Studies. DDM analogs were synthesized employing the Smith gram-scale synthetic route (Smith et al., 1999, 2000) with minor modifications. As shown in Fig. 1B, the primary paramethoxylbenzyl ether in compounds D1-3 was selectively removed using 1.1 equivalents of $\mathrm{BCl} 3$ in $\mathrm{DCM}$ at $0^{\circ} \mathrm{C}$. The resulting primary alcohol was converted to the corresponding iodide that was used without further purification in the next step due to the instability to provide the phosphonium salt E1-3. Treatment of the phosphonium salt E1-3 with sodium bis(trimethylsilyl) amide followed by the addition of the aldehyde fragment $\mathrm{A}$ led to the Wittig olefination products $\mathrm{F}$. The para-methoxylbenzyl protecting group was then removed using 1.2 equivalents of dichlorodicyanobenzoquinone followed by the introduction of the carbamate. Subsequent global deprotection of the tert-butyldimethylsilyl groups afforded DDM analogs A1-3. DDM analogs B1-3 and C1-3 were prepared in the same manner using aldehydes B and C. All compounds were dissolved in DMSO for cell-based analysis and diluted in culture media, such that the DMSO concentration was less than $0.01 \%$. Methods for chemical synthesis and X-ray crystallography are provided in Supplemental Methods. Data collection and refinement statistics for $\mathrm{T}_{2} \mathrm{R}$-TTL-B2 are provided in Supplemental Table 6, and a simulated annealing electron density omit map highlighting the validity of the model is shown in Supplemental Fig. 5. The atomic coordinates and structure factors have been deposited in the Research Collaboratory for Structural Bioinformatics Protein Data Bank (www.rcsb.org) under accession number 6SES.

Cell Lines. Ovarian cancer, triple-negative breast cancer (TNBC), and lung cancer cell lines (SKOV3, IGROV1, HCC38, HCC1143, BT549, HS578T, HEY, A549, NIH-H460) and the BRCA mutant TNBC cell lines (HCC1937, MDA-MB-436) were purchased from American Type Culture Collection (Manassas, VA) and grown according to vendor recommendations. All cell lines were confirmed to be mycoplasma negative (MycoAlert detection assay; Lonza) prior to use and early passages $(<20)$ used. BRCA mutant SUM149PT cells were obtained from Dr. Steve Ethier, University of Michigan. All cell lines were authenticated by short tandem repeat profiling before purchase or use in this study. The resistant cell lines SKVLB and HeyTx100, derived from SKOV3 and HEY ovarian carcinoma cells, respectively, have been previously described (Bradley et al., 1989; Yang et al., 2018). Upon thawing they were grown in the presence of either vinblastine or taxol for two passages and subsequently cultured in drug-free media for a further two passages before use in experiments.

Cell Proliferation Assays. Standard cell proliferation assays were performed using both sulforhodamine B (SRB) to measure total protein in adherent cells (Skehan et al., 1990). Cells were seeded at 1-3 $\times 10^{4}$ cells $/ \mathrm{ml}$ into 96 -well plates, and 24 hours later incubated with serial dilutions of congeners (2-fold), spanning nine dose levels, typically ranging from 250 to $1 \mathrm{nM}$ ( $n=6$ wells per dose level). Cells were incubated for three doublings (3-7 days) without replenishing. The anticancer effect was computed relative to vehicle-only treated control cells, and sigmoidal dose-response curves were generated as described (Fallahi-Sichani et al., 2013). Resistant cell lines required a wide range of doses $(1 \mu \mathrm{M}$ to $0.01 \mathrm{nM})$ to generate sigmoidal doseresponse curves.

To assess the ability of congeners to suppress tumor cell proliferation in the long term, duplicate plates were also set up and analyzed approximately 3 weeks later, without replenishing media or congeners. In some cases, these data were reported as drug effect without normalization as control cells continued to proliferate over the duration of the experiment and eventually died, such that normalization could not be performed. SKOV3 cells are more taxol-sensitive relative to $\mathrm{HEY}$; therefore, lower doses of all compounds were evaluated in this cell line.

For some experiments, the effect on congeners on cancer cell survival and proliferation was confirmed by a 3-(4,5-dimethylthiazol-2-yl)-5-(3-carboxymethoxyphenyl)-2-(4-sulfophenyl)-2H-tetrazolium (MTS) assay that measures NADPH/NADH production by dehydrogenase enzymes to reduce an MTS tetrazolium compound. The advantage of this method is that viability of both adherent and nonadherent cells can be determined (Segu et al. 1998).

Multiparameter Dose-Response Analysis. Data were analyzed as described previously (Fallahi-Sichani et al., 2013), whereby logtransformed values were fitted to a sigmoidal model using nonlinear least squares regression using the $R$ statistical software suite 
(http://www.R-project.org/). The features of interest, specifically $\mathrm{EC}_{50}$, $\mathrm{E}_{\mathrm{Max}}, \mathrm{AUC}$, and Hill slope, were computed in R from the fitted model. AUC was estimated using numerical integration ( $R$ function integrate) over the fitted model. The code is available upon request. $\mathrm{E}_{\mathrm{Max}}$ (efficacy) is the maximum response achievable from a molecule. $\mathrm{EC}_{50}$ (potency) is the drug concentration corresponding to the halfmaximal effect. AUC is a metric that represents the area under the relative viability curve, defined as the sum of measured responses, and combines potency and efficacy into one single parameter. Data were plotted in $\mathrm{R}$ and graphed as box and whisker plots depicting median (horizontal line) and interquartile range (boxes). Cancer cell lines with a Hill slope $<1$ and AUC $<4.0$ for taxol were categorized as taxol resistant (Supplemental Table 1) and analyzed as a separate cohort.

Statistics. With the exception of multiparameter dose-response analyses, all statistical analyses were performed using GraphPad Prism version 8 (GraphPad Software Inc.). Student's $t$ tests were used to determine statistical significance of differences between the two groups. Where relevant, $P$ values reported are from Dunnett's post hoc tests, adjusted for multiple variances. Equal variances analysis of $\mathrm{E}_{\mathrm{Max}}$ and AUC between different congeners and taxol was done using a one-tailed F-test (Morgan, 1939). Differences were considered statistically significant at $P<0.05$ with $0.01-0.001$ being very significant and 0.001-0.0001 extremely significant.

Reactive Oxygen Species Generation. Reactive oxygen species (ROS) was measured in asynchronous and drug-treated HEY and A549 cells $(n=6)$ seeded in 96-well light-sensitive plates. Cells were treated with $\mathrm{E}_{\mathrm{Max}}$ doses of taxol, DDM, or congeners (A1, A2, A3, B1, $\mathrm{B} 2$, and B3) for 3 hours prior to loading with $10 \mu \mathrm{M}$ H2DCFDA (a fluorogenic reagent that detects reactive oxygen intermediates in cells) in PBS for 40 minutes at $37^{\circ} \mathrm{C}$ in the dark to detect intracellular ROS (mean fluorescence intensity). Since congeners $\mathrm{C}$ had the weakest anticancer activity, they were not evaluated. $\mathrm{H}_{2} \mathrm{O}_{2}$ was used as a positive control. Fluorescence output was measured via plate reader (488 $\mathrm{nm}$ excitation/535 $\mathrm{nm}$ emission), and mean ROS production \pm S.D. was determined after subtraction of background fluorescence. There was no loss of cell viability within the 3-hour treatment period.

Determination of Senescence. Ninety-six-well plates of cells were set up as described for cell proliferation assays to determine senescence induction. After at least 6 days' treatment with various compounds (the minimal amount of time required to establish a stable senescent culture following exposure to cytotoxic compound), plates were processed for senescence-associated $\beta$-galactosidase (SA- $\beta$-gal) (Itahana et al., 2007). Positive cells were identified as having blue cytoplasmic staining coupled with an enlarged, granular cytoplasm using standard light microscopy at 10-20× magnification. Data were expressed relative to the number of SA- $\beta$-gal negative cells to differentiate between senescence and nonsenescent drug-tolerant cells that survive treatment. This assay was not informative for senescent SKOV3 cells.

Transwell Invasion Assay. Boyden Chamber assays were performed using BD Biocoat Matrigel Invasion Chambers. BT549 (metastatic TNBC) cells were seeded at $5 \times 10^{5}$ cells per chamber containing $0.5 \%$ serum. $\mathrm{E}_{\text {Max }}$ concentrations of test compounds were added, and invasion of cells through matrigel in response to a $0.5 \%-10 \%$ serum gradient was quantified 20 hours later by fixing membranes and staining invaded cells with crystal violet. Cells were counted by microscopy, excluding edges to determine the invasion rate (normalized to the effect of test compounds on cell viability by setting up identical plates without chamber inserts and quantifying the cell number 20 hours after treatment initiation). Data were expressed relative to vehicle-treated control, and experiments were repeated a minimum of three times.

Evaluation of Gene Expression in Cancer Cells Treated with Taxol or DDM Congeners. Total RNA was isolated from cells treated with various congeners using RNAeasy, and cDNAs were synthesized using the Superscript VILO Reverse Transcriptase. Realtime quantitative reverse-transcription polymerase chain reaction was performed using SYBRGreen I Master (Roche) and run on a LightCycler 480 (Roche) to determine expression of the epithelial to mesenchymal transition (EMT)-related genes, Twist, slug, snail, Vimentin, and CDH2. Expression was normalized to cyclophilin B and normalized to vehicle-treated controls. Experiments were performed in triplicate. Primers were designed using PrimerBank (http://pga. mgh.harvard.edu/primerbank).

\section{Results}

Synthesis of Simplified DDM Congeners. The main goal of this study was to refine the chemical structure of DDM, building on prior optimization studies focused on the lactone and diene regions (Fig. 1A). We hypothesized that monosaturation of the diene and addition of a methyl at $\mathrm{C}(4)$ of the lactone could limit oxidation and prevent metabolic degradation (Shaw et al., 2006), potentially modulating anticancer activity. Additionally, since conformationally rigid five-membered ring congeners demonstrated promising activity in previous studies (Shaw et al., 2005), diene-saturated variants of these were also synthesized (Fig. 1B), culminating in a series of congeners available for testing (Fig. 1C).

Multiparameter Analysis of Dose-Response Relationships Identifies Lead DDM Congeners. The anticancer activity of DDM congeners was determined in a panel of genetically heterogeneous human breast (TNBC) and ovarian cancer cell lines by multiparametric dose-response analyses, as described (Fallahi-Sichani et al., 2013). Median $\mathrm{E}_{\text {Max }}$, AUC, and $\mathrm{EC}_{50}$ values were computed for all cell lines (Supplemental Table 1), and distribution was plotted (Fig. 2A). AUC and $\mathrm{EC}_{50}$ were statistically significantly different for DDM and taxol across all cell lines. Moreover, congeners A2 and B2 had the most significantly increased AUC $(P<0.0001)$ and $\mathrm{EC}_{50}(P=$ 0.0002-0.0001) relative to DDM (Supplemental Table 2). No significant differences in $\mathrm{E}_{\mathrm{Max}}$ were evident for any of congener versus either taxol or DDM.

Dose-response plots for all data illustrate the variation in dose-response relationships for the four molecules, despite shared mechanism of action (Fig. 2B). DDM generated more linear shaped plots relative to the sigmoidal plots typical of taxol and congeners B2 and A2. Variances in the median AUC or $\mathrm{E}_{\mathrm{Max}}$ of the congeners relative to taxol were evaluated using an F-test (Supplemental Table 3). The variation in median $\mathrm{E}_{\mathrm{Max}}$ for B2 (but not A2) indicate some difference compared with taxol (F statistic, $P=0.032$ ), with a trend toward significance for AUC also $(P=0.070)$, suggesting that $\mathrm{B} 2$ may generate a uniform pharmacologic response relative to taxol. However, this statistical significance may not hold after adjusting for multiple testing.

Definition of the Optimal C(21)-C(24) Terminus and Lactone Structural Elements of DDM. Epoxidation of the $\mathrm{C}(21)-\mathrm{C}(22)$ or $\mathrm{C}(23)-\mathrm{C}(24)$ diene was hypothesized to contribute to enzymatic degradation (Fan et al., 2009); therefore diene-monoene-saturated congeners were synthesized for evaluation. Saturated analogs (A3, B3, and C3) had weak anticancer activity irrespective of lactone, evident as high $\mathrm{EC}_{50}$ and low $\mathrm{E}_{\mathrm{Max}}$ and AUC (Fig. 2B; Supplemental Table 1). Median $\mathrm{E}_{\text {Max }}$ for diene versus monoene congeners was comparable; however, monoenes (A2 and B2) had higher AUC and lower $\mathrm{EC}_{50}$ compared with dienes (A1 and B1) across all cell lines, though not statistically significant. Turning to the lactone, the addition of a second methyl group at the C(4) 


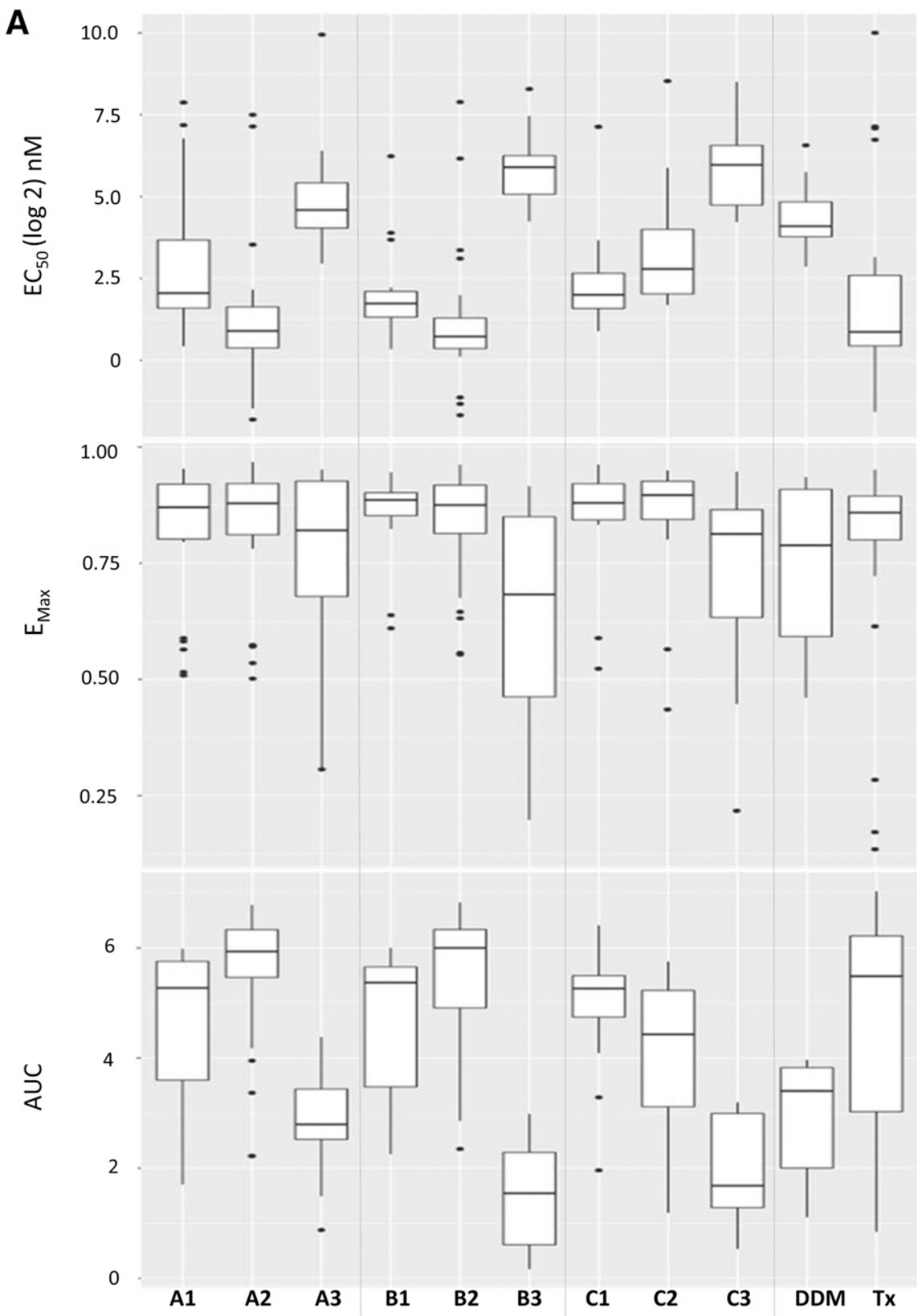

Fig. 2. Analysis of dose-response parameters for DDM, taxol, and novel DDM congeners across 12 TNBC and ovarian cancer cell lines identifies A2 and $\mathrm{B} 2$ as promising anticancer leads. (A) Variation in dose-response parameters for DDM, taxol (Tx), and congeners (A1-C3) across 12 TNBC and ovarian cancer cell lines. Values were computed from sigmoidal dose-response curves. Analysis parameters are $\mathrm{EC}_{50}$ (potency), $\mathrm{E}_{\mathrm{Max}}$ (efficacy), and AUC (potency and efficacy combined). Data are represented as box and whisker plots with median (horizontal line) and interquartile range (boxes) shown. Bars extending to $1.5 \times$ the interquartile range indicate variance for each parameter, and outliers are shown as nonconnected data points. (B) Dose-response curves depicting variation in doseresponse relationships ( $n=12$, taxol: $n=15$ for $\mathrm{DDM}, \mathrm{A} 2$ and B2). Morgan testing indicates a statistically significant difference in the $\mathrm{E}_{\mathrm{Max}}$ of $\mathrm{B} 2 \mathrm{vs}$. taxol (F statistic, $P=0.032$ ), although significance diminishes after adjustment for multiple testing.

B

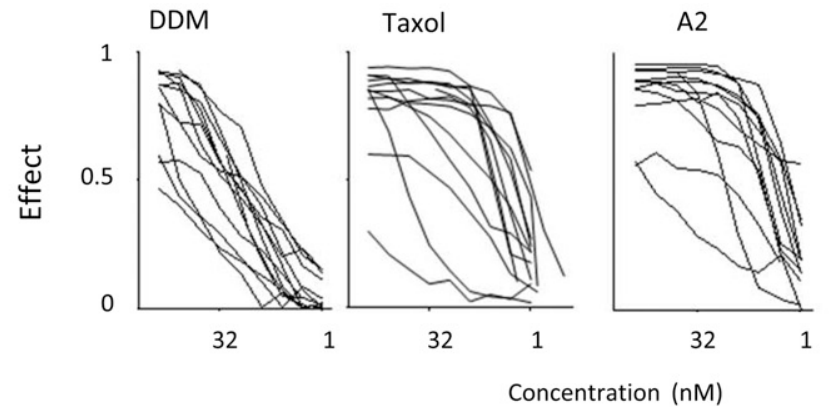

B2

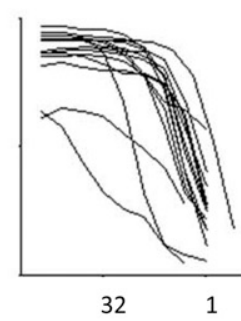

position to form a gem dimethyl (congeners A1-A3) was designed to block oxidative metabolism of the $\mathrm{C}(4)-\mathrm{C}(5)$ bond; however, there was only a subtle difference in dose-response parameters of these analogs relative to the $\mathrm{B}$ series that have one methyl at $\mathrm{C}(4)$ (Fig. 2B). In contrast, lactone congeners

with five-membered rings (series C) had weaker anticancer activity relative to both the $\mathrm{A}$ and $\mathrm{B}$ series. Within the $\mathrm{C}$ series, the diene-containing analog $\mathrm{C} 1$ was most active (Fig. 2A). Therefore, a DDM congener with a monoene and one C4methyl is the optimal conformation for anticancer activity. 
TABLE 1

ROS generation in DDM- and congener-treated cells Ovarian cancer cells (HEY) and NSCLC cells (A549) were treated with $\mathrm{E}_{\mathrm{Max}}$ doses for 3 hours prior to loading with $10 \mu \mathrm{M} 2^{\prime}, 7^{\prime}$-dichlorodihydrofluorescein diacetate to detect intracellular ROS (measured as fluorescence intensity). Taxol induced ROS at levels comparable to $\mathrm{H}_{2} \mathrm{O}_{2}$, whereas DDM induced ROS to a lesser extent. All congeners had statistically significantly reduced ROS activation compared with DDM in both cell lines (Dunnett's multiple comparison test). There was no statistically significant difference in ROS between congeners (e.g., A1 vs. A2) for either cell line (data not shown). Data represent means \pm S.D. of three independent experiments. $\mathrm{H}_{2} \mathrm{O}_{2}$-treated cells were used as a positive control.

\begin{tabular}{|c|c|c|c|c|}
\hline & \multicolumn{2}{|l|}{ HEY } & \multicolumn{2}{|l|}{ A549 } \\
\hline & Fluorescence intensity \pm S.D. & $P$ & Fluorescence intensity \pm S.D. & $P$ \\
\hline DDM & $\begin{array}{c}\chi \\
435 \stackrel{1}{ \pm} 163.7\end{array}$ & - & $415 \stackrel{\chi}{ \pm} 59.5$ & - \\
\hline Taxol & $1667 \pm 468.3$ & $* * * *$ & $1546 \pm 522.8$ & $\mathrm{~ns}$ \\
\hline A1 & $173 \pm 22.0$ & $* * * *$ & $145 \pm 11.1$ & ** \\
\hline A2 & $177 \pm 18.1$ & $* * *$ & $146 \pm 11.0$ & $*$ \\
\hline A3 & $172 \pm 44.7$ & $* *$ & $148 \pm 6.6$ & $*$ \\
\hline B1 & $221 \pm 32.0$ & $* *$ & $204 \pm 39.4$ & * \\
\hline B2 & $199 \pm 21.1$ & $* * *$ & $170 \pm 16.2$ & ** \\
\hline B3 & $184 \pm 33.9$ & $* *$ & $161 \pm 12.2$ & $*$ \\
\hline $\mathrm{H}_{2} \mathrm{O}_{2}$ & $1978 \pm 257.3$ & $* * * *$ & $1703 \pm 116.0$ & $*$ \\
\hline
\end{tabular}

DDM Congeners Do Not Exhibit Significant Changes in Reactive Oxygen Species Generation. Since DDM can be differentially oxidized at numerous sites including $\mathrm{C}(4)-\mathrm{C}(5)$ and $\mathrm{C}(21)-\mathrm{C}(22)$ or $\mathrm{C}(23)-\mathrm{C}(24)$, we hypothesized that enzymatic hindrance at these sites could limit metabolic degradation. High ROS from mitochondrial oxidative damage in cells are associated with either senescence (Ziegler et al., 2015), cell death, or proliferation, depending on the cellular context (Olsen et al., 2013; Ogrunc et al., 2014). We hypothesized that metabolic degradation of DDM could generate high ROS, potentially causing senescence; therefore, we measured ROS generation as a surrogate for metabolic degradation. All congeners had reduced ROS relative to DDM within the parameters tested (Supplemental Fig. 1; Table 1). Levels were similar across A and B series suggesting that a simplified lactone structure and not the $\mathrm{C} 4$ constituent (methyl or gem-dimethyl) had the strongest influence on ROS generation. Similarly, there was no statistically significant difference in ROS levels that correlated with diene saturation. Taxol generated ROS at levels comparable to the positive control, $\mathrm{H}_{2} \mathrm{O}_{2}$, and at statistically higher levels compared with DDM $(P<0.05)$; however, taxol is a weak inducer of senescence (Klein et al., 2005). Furthermore, comparing ROS generation with dose-response parameters (Fig. 2) and CIS (Fig. 4E), we conclude that ROS levels do not correlate with anticancer efficacy or CIS under the conditions evaluated here.

Identification of DDM Congeners with Activity in Taxol-Resistant Cell Models. To facilitate a nuanced doseresponse relationship analysis, we dichotomized data into taxol-resistant versus taxol-sensitive cohorts. Resistant cell lines were identified as having AUC $<4$ and Hill slope $<1$ (Supplemental Table 4), consistent with previously described features (Sampah et al., 2011; Fallahi-Sichani et al., 2013). Analysis of sensitive cell lines indicated similar median AUC and $\mathrm{EC}_{50}$ among congeners $\mathrm{A} 2$ and $\mathrm{B} 2$ versus taxol (Fig. 3). In contrast, taxol had a weak anticancer effect in resistant cell lines, whereas both A2 and B2 had statistically significantly improved AUC $(P=0.017$ and $P=0.0072$, respectively) (Supplemental Table 4). Similarly, A2 and B2 had significantly improved $\mathrm{EC}_{50}$.

Congener B2 Has Superior Long-Term Efficacy Compared to Taxol. Reported values for $\mathrm{EC}_{50}$ and $\mathrm{E}_{\mathrm{Max}}$ for a given cell line often vary widely due to differences in assay type and failure to tailor assays to account for differences in doubling time (Hafner et al., 2016), though our experimental design accounted for this. Colony-forming assays can be used to monitor longer-term anticancer efficacy; however, low seeding densities can artificially inflate efficacy metrics (Hafner et al., 2016). To circumvent this, we extended the duration of standard proliferation assays from three cell doublings to approximately 3 weeks without congener replenishment to evaluate long-term anticancer effect.

As shown for the ovarian cancer cell line HEY, doseresponse curves for taxol and B2 were overlapping after three cell doublings (Fig. 4A) indicating almost identical effect. However, by day 21 (Fig. 4B), the dose-response curve for taxol was more shallow with substantially reduced AUC due to regrowth of transiently growth-arrested cells. Impressively, B2-treated cells sustained a strong anticancer response evident by day 21. Images of SRB-stained plates are shown at days 3 and 21 (Fig. 4, C and D). Measurement of mitochondrial oxidoreductase activity in both adherent and nonadherent drug-treated cells (MTS) also confirmed these findings (Supplemental Fig. 2). Since multiparameter analysis also indicated promising activity of congener A2, we contrasted the long-term effect of A2 versus B2 (Supplemental Fig. 2, C and D) and found that both had superior long-term activity compared with taxol; however B2 had the most sustained effect. As a control, the long-term activity of cisplatin (US Food and Drug Administration-approved therapy for serous ovarian cancer) was determined and found to have weak anticancer effect in HEY cells (Supplemental Fig. 2E). In conclusion, congener B2 displayed superior short- and long-term activity relative to taxol, cisplatin, and other DDM congeners. The effect of B2 was also evaluated in SKOV3 ovarian cancer cells (Supplemental Fig. 3), where short- and long-term analysis (4 days and 3 weeks) again indicated superior activity of B2 compared with taxol.

Attenuation of CIS by Congener B2. Since CIS is a major outcome of DDM exposure (Klein et al., 2005; Chao et al., 2011), we evaluated the lead congener, B2, for senescence inducing properties. HEY cells are amenable to senescence quantitation using the SA- $\beta$-gal assay (Itahana et al., 2007); therefore, four 
Sensitive

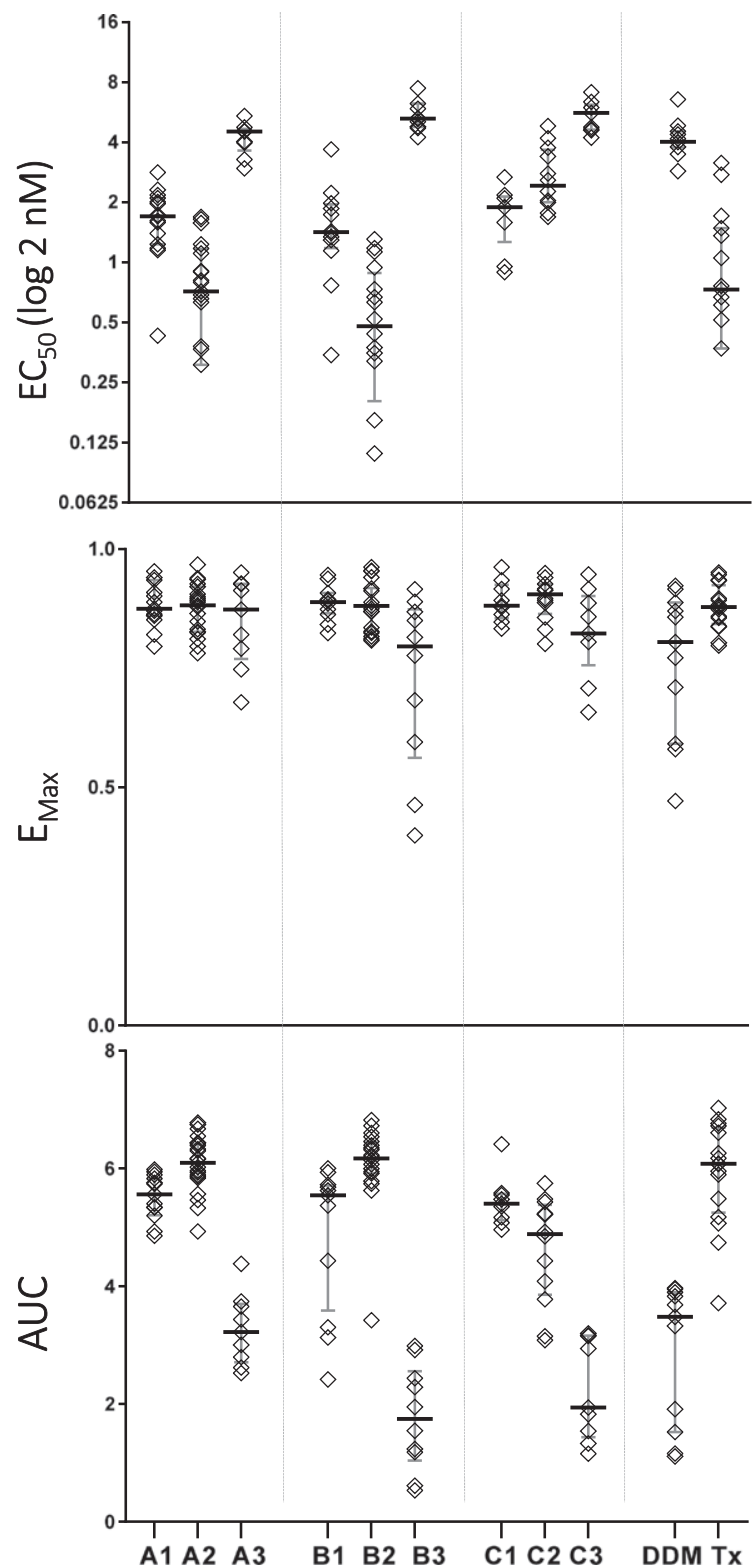

Resistant

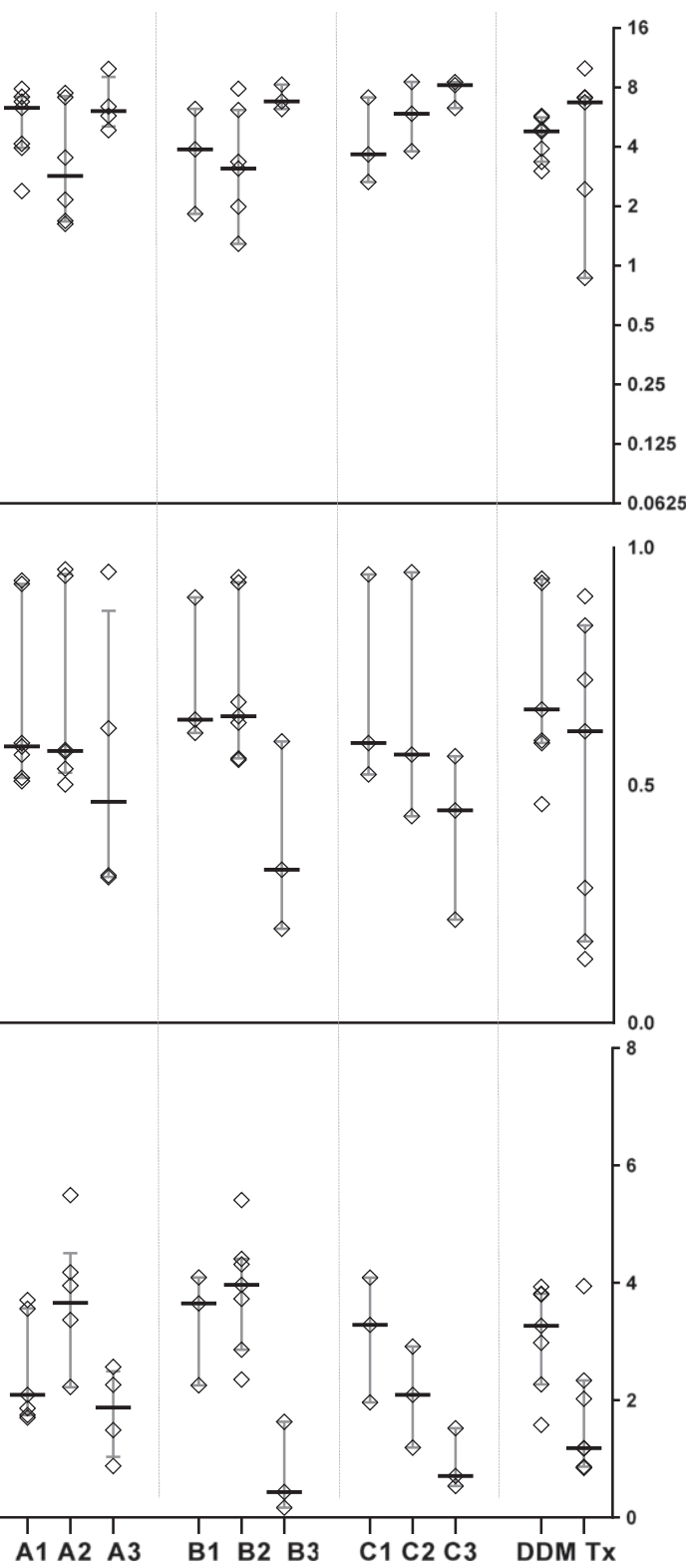

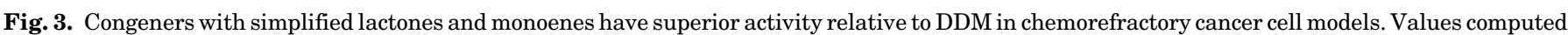

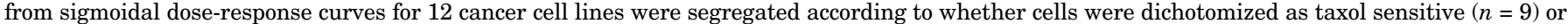

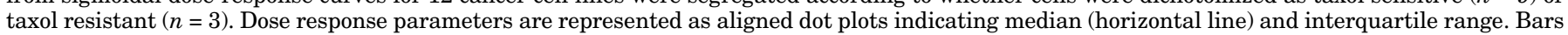
extending to $1.5 \times$ the interquartile range are also indicated. Outliers are represented by nonconnected data points.

dose levels, approximating to $\mathrm{E}_{\mathrm{Max}}, \mathrm{EC}_{50}$, and $>\mathrm{EC}_{50}$, were evaluated for SA- $\beta$-gal positivity (Supplemental Table 5). As shown in Fig. 4E, DDM strongly induced senescence at $50 \mathrm{nM}$, a dose that approximated the 6 -day $\mathrm{EC}_{50}$. In contrast, taxol was a weak inducer of senescence, consistent with previous reports (Klein et al., 2005). Congener B2 had significantly reduced senescence relative to DDM at $50 \mathrm{nM}(P<0.01$ : analysis of variance with post hoc test), although the phenotype was still detected at a lower dose (Supplemental Table 5). Thus, at doses approximating the $\mathrm{EC}_{50}$, congener $\mathrm{B} 2$ had attenuated risk of CIS relative to DDM.

We recently demonstrated that taxol does not possess significant senolytic activity, defined as the ability to induce senescent cell death (Samaraweera et al., 2017). Cisplatin and the histone deacetylase inhibitor panobinostat, however, have strong senolytic activity. Thus, we evaluated the ability of DDM and congeners B2 and A2 to kill senescent HEY or A549 cells and found that like taxol, they possess little to no senolytic activity (Supplemental Fig. 4).

Superior Antimetastatic Properties of Congener B2. Since cancer mortality is primarily due to metastatic dissemination, we investigated the effect of congener B2, taxol, and DDM on metastatic parameters in BT549 (Fig. 5), an invasive, mesenchymal TNBC cell line (Lehmann et al., 2011). Images of congener-treated cells are shown to illustrate differential effects on morphology and proportion of surviving cells. The effect of the various tubulin ligands on EMT-associated genes in surviving, adherent cells was also evaluated. Expression of 
A
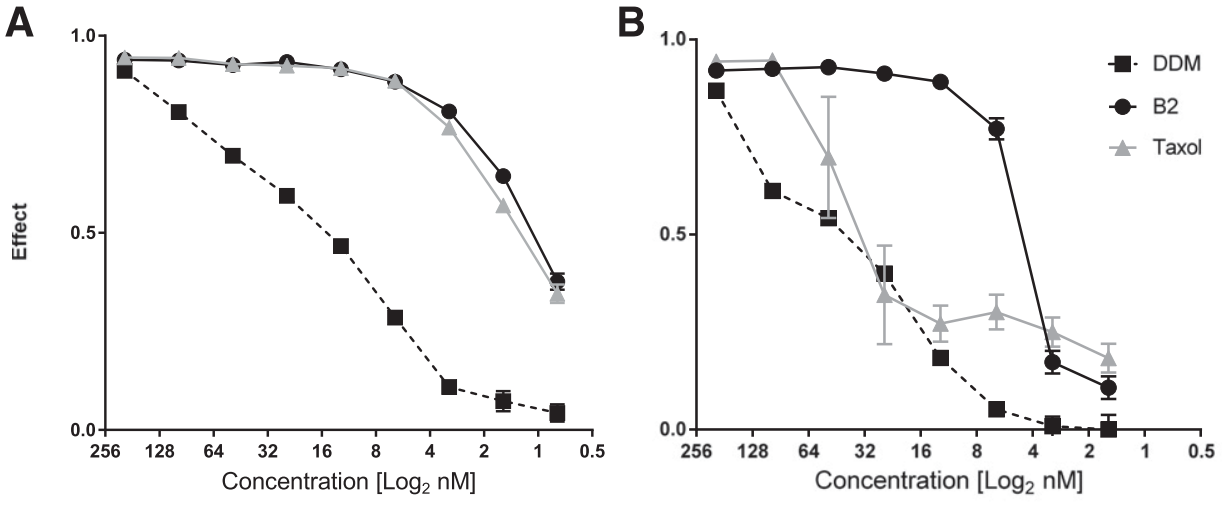

C
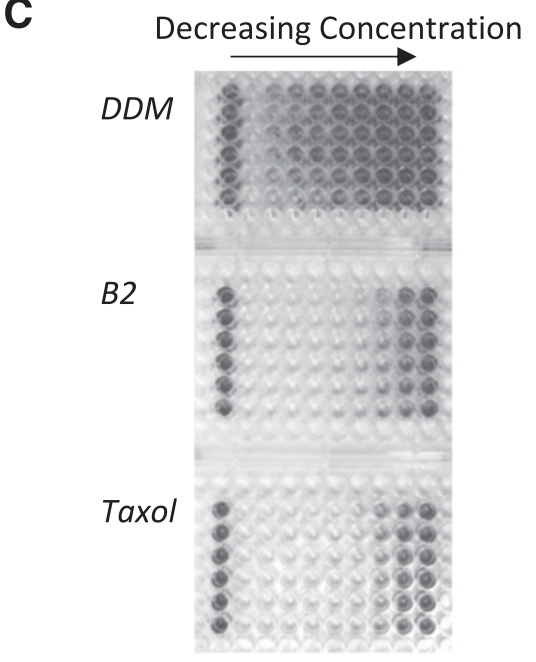

E

CONCENTRATION:
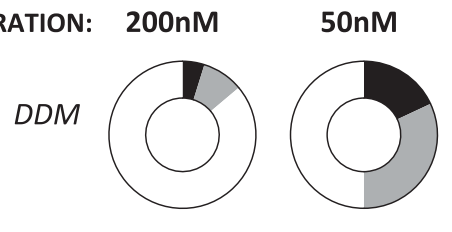

$6.25 \mathrm{nM}$
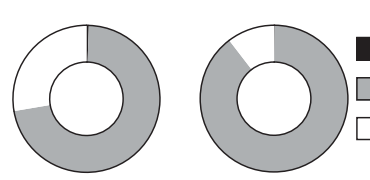

Senescent

Proliferating

B2
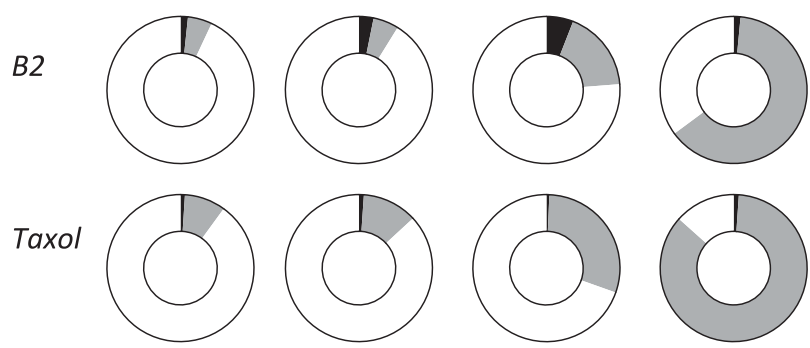

Fig. 4. Superior long-term efficacy of congener B2 in HEY cells. Dose-response curves for DDM, B2, and taxol in HEY cells after three cell doublings (3 days) (A) and 21 days without replenishing compounds or media (B). Representative images of SRB-stained plates corresponding to 3 days $(\mathrm{C})$ and 21 days (D) are shown. (E) Quantitation of cell fate in drug-treated HEY cells after 6 days of treatment with DDM, B2, or taxol. Data were derived by quantifying percentage of SA- $\beta$-gal+ cells, a metric of senescence, as a proportion of drug effect. DDM strongly induced senescence relative to taxol, whereas B2 induced senescence at an intermediate rate. B2 demonstrated a prolonged anticancer effect, evident 3 weeks after dosing. the transcription factors snail and slug, known regulators of EMT (Nieto et al., 1994; Batlle et al., 2000), was increased by taxol and DDM treatment, whereas B2-treated cells exhibited a statistically significantly decreased expression of all five genes comprising the EMT signature, relative to vehicle-only control ( $P>0.0001$ : unpaired $t$ test). The effect of taxol, DDM, or B2 on BT549 invasion through matrigel was also evaluated (Fig. 5C). All three suppressed invasion relative to vehicleonly controls; however, the effect was most pronounced for DDM and B2, though not statistically significant. Thus, congener
B2 treatment imparts favorable antimetastatic properties in this aggressive model of mesenchymal TNBC.

Congener B2 Binds to the Taxane Site with a Shifted Lactone Compared with DDM. The binding mode of DDM in the taxane pocket of $\beta$-tubulin has recently been described in great detail by X-ray crystallography (Prota et al., 2017). To provide critical insights into the molecular mechanism of action of the lead congener, B2, we determined the crystal structure of a tubulin-B2 complex to $2.0 \AA$ resolution (Fig. 6). $\mathrm{B} 2$ bound to the taxane site on $\beta$-tubulin in a very similar 
A

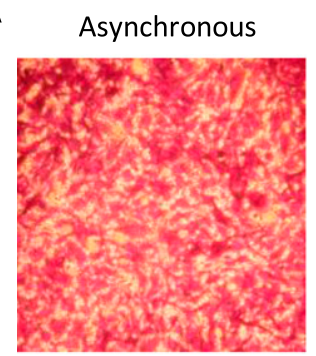

B

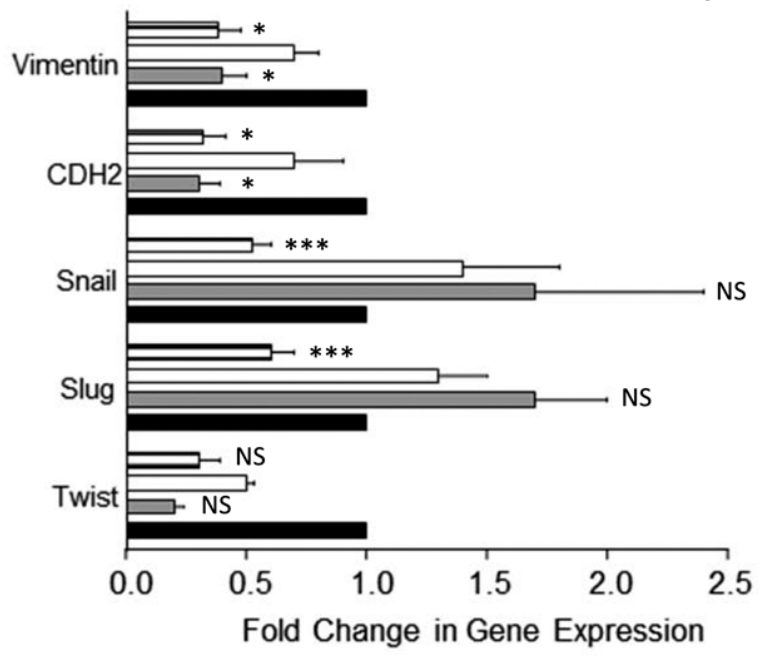

B2

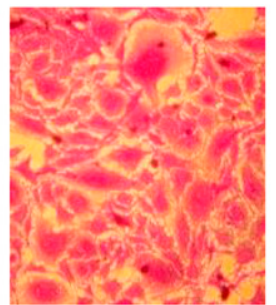

Taxol

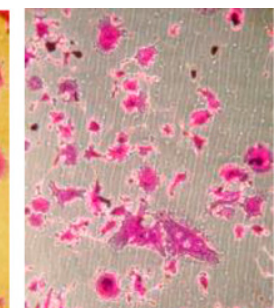

C

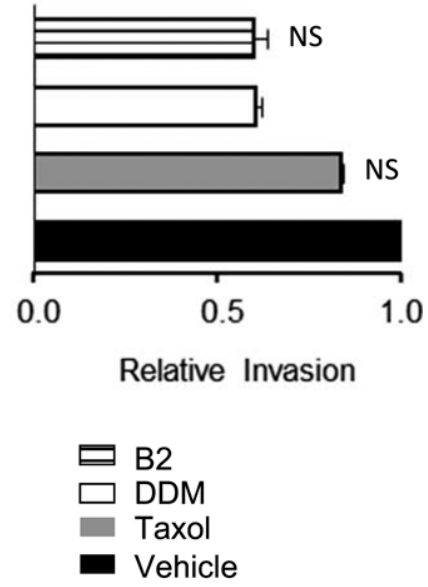

Fig. 5. Antimetastatic activity of $\mathrm{B} 2$ in chemorefractory TNBC cells. BT549 cells were exposed to either $\mathrm{EC}_{50}$ doses of DDM, $\mathrm{B} 2$, or taxol for 4 days $(\mathrm{A}, \mathrm{B})$ or $\mathrm{E}_{\text {Max }}$ doses for 24 hours $(C)$ and subsequently assayed for metastasis-related endpoints. (A) SRBstained cells show enlarged, flat cells emerging after DDM treatment, consistent with emergence of a senescent phenotype. In contrast, B2- and taxol-treated cells have reduced numbers of surviving cells that do not have the same morphology. (B) Analysis of a five-gene metastatic signature following the various treatments indicates a statistically significant decrease in expression relative to the effect of either taxol or DDM. Statistical significance for $\mathrm{B} 2$ and taxol compared with DDM is indicated. (C) 24-hour treatment of BT549 with taxol, DDM, or B2 partially suppresses invasion through matrigel. Statistical significance relative to DDM (unpaired $t$ test) is indicated. Data represent means \pm S.D. of three independent experiments. $* P<0.05 ; * * * P<0.001-0.0001 ; \mathrm{NS}$, not significant. hairpin conformation as DDM (Fig. 6A), and the majority of the interactions were conserved. However, compared with DDM, the absence of both the C2-methyl and the C3-hydroxyl in $\mathrm{B} 2$ gave rise to a loss of one hydrogen bond to the backbone of Arg369 and a reorientation of the lactone ring in the pocket (Fig. 6B). Moreover, a smaller reorientation of the C23 and C24 section of the monoene sidechain was observed, which caused a minor shift of the Arg278 sidechain. These observations demonstrate that B2 binds to the taxane site on $\beta$-tubulin. They further suggest a better adaptation capability to changes in the taxane-binding site of congener B2 compared with DDM.

We further superimposed the taxol-bound MT structure (Fig. 6C, Protein Data Bank identifier 5SYF) onto the taxane site of the tubulin-B2 complex (root mean square deviation of $0.99 \AA$ over $49 \mathrm{C}_{\alpha}$-atoms). Compared with taxol, B2 and DDM occupied the structural cavities previously reported (Prota et al., 2017) by positioning their lactone rings between the C4acetyl and the 3 '-phenyl moieties, relative to taxol. There were also significant differences in the orientation of Arg 278 by DDM and B2 versus taxol, which are potentially significant for future molecular dynamic studies, since amino acids Ser 277 and Arg 278 are variant among human tubulin isotypes. Overall, these data provide structural insights in support of a favorable occupation of B2 in the binding pocket of tubulin that associate with improved biologic activity relative to DDM.

\section{Discussion}

Cytotoxic chemotherapies cause an array of fates in tumors, including apoptosis, necrosis, mitotic catastrophe, and the dormancy phenotypes, quiescence and senescence. CIS is an unintended consequence of cancer treatment that imparts long-term consequences that may contribute to accelerated aging in cancer survivors and increased risk of developing a secondary malignancy, reviewed in Childs et al., 2015. Thus, minimizing risk of CIS is an important but underappreciated consideration in anticancer drug development. We have implemented a robust strategy to select molecules that maximize tumor cell death while minimizing CIS based on increasing $\mathrm{E}_{\mathrm{Max}}$ and AUC and steepening the Hill slope (Fallahi-Sichani et al., 2013; Nadaradjane et al., 2018). This multiparametric approach best maximizes leads for further development, evolving contemporary drug discovery beyond an $\mathrm{EC}_{50}$-centric approach and thereby lessening the risk of developing compounds that strongly induce CIS.

Although the tumor-suppressive effects of senescence prevents the replication of damaged cells that could potentially become malignant, this applies primarily to young cells and tissues (Baker et al., 2011; Braumüller et al., 2013; Storer et al., 2013; Flach et al., 2014; Katsimpardi et al., 2014). However, in cancer cells, the integrity of the cell cycle regulatory apparatus is compromised such that they can escape or bypass senescence, enabling malignant cell expansion (Damsky et al., 2015; Sharpless and Sherr, 2015; Le Duff et al., 2018). For this reason, prosenescent cancer therapies have largely fallen out of favor due to concerns regarding chronic SASP signaling and tumor evolution (Milanovic et al., 2018). A significant exception to this, however, is the approval of combined CDK4/6 inhibitors with antiestrogens for the treatment of estrogen receptor-positive, human epidermal growth factor receptor 2-negative breast cancer (Wolff, 2016). The mechanism of action is partially attributable to senescence induction in tumors that retain retinoblastoma function, 
A

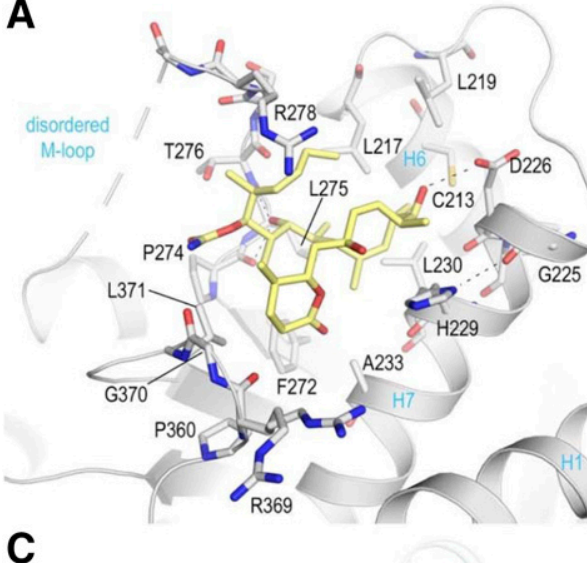

C

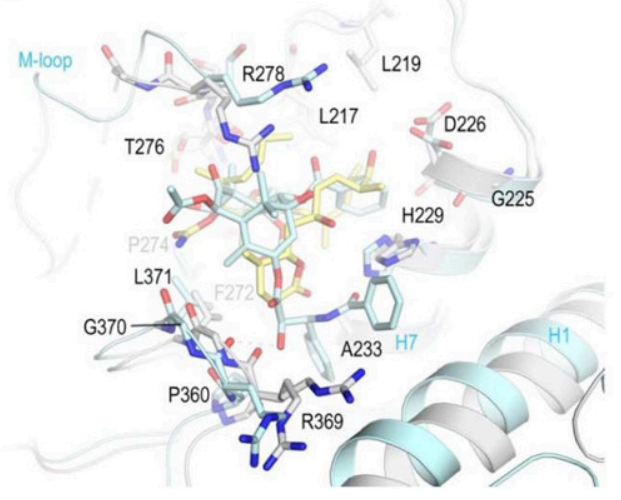

B

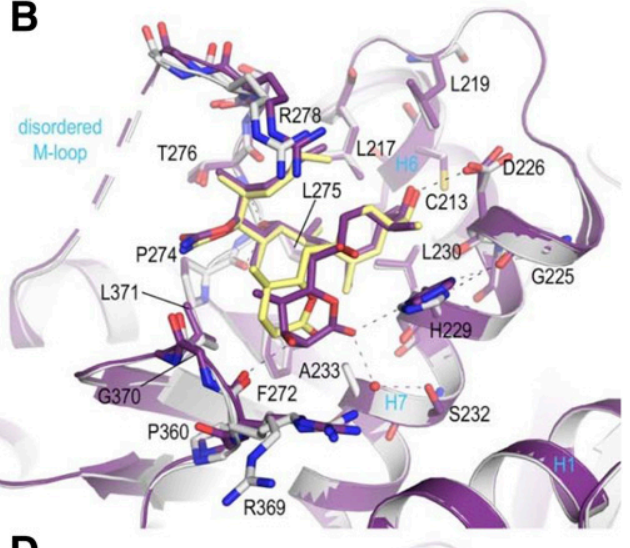

D

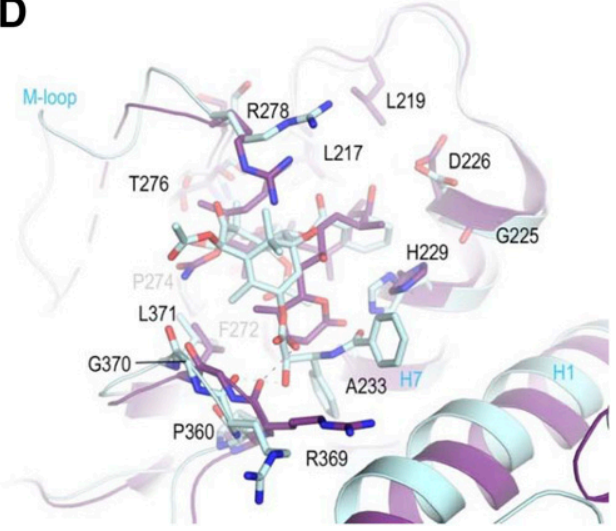

Fig. 6. Structure of the tubulin-B2 complex infers optimal adaptation in the taxane-binding pocket. (A) Close-up view of the interactions observed between congener B2 (yellow) and $\beta$-tubulin in white stick and ribbon representation. Hydrogen bonds are depicted as black dashed lines, water molecules as red spheres. (B, C) Close-up view of the superimposed tubulin-DDM (violet purple) (B) and paclitaxel-stabilized microtubule (pale cyan, Protein Data Bank identifier 5SYF) (C) complexes in stick and ribbon representation. (D) The complexes were superimposed onto their corresponding taxane-site residues $208-219,225-237$, 272-276, 287-296, 318-320, and 359-376 (root mean square deviation ${ }_{\text {DDM }} 0.12\left[45 \mathrm{C}_{\alpha^{-}}\right.$ atoms]; root mean square deviation paclitaxel 0.9 [49 $\mathrm{C}_{\alpha}$-atoms]). with subsequent immune-mediated clearance in some patients (Knudsen and Witkiewicz, 2017) Thus, it is hypothesized that therapy-mediated senescence in tumors with intact G1/S checkpoint function and a low prevalence of genetic alterations can lead to favorable clinical outcome (Knudsen and Witkiewicz, 2017). However, the majority of solid malignancies approved for treatment with taxol, including breast and ovarian cancers, do not meet these criteria; therefore, drug effect is highly variable, as demonstrated by our dose-response modeling. In light of these considerations, it is significant that the lead DDM congener, B2, has a more uniform dose-response profile relative to taxol and DDM, despite the significant genetic variability of the cell lines tested.

We set out to define, synthesize, and test congeners for potent anticancer activity including diminished risk of CIS, a dominant mechanism of action of DDM (Klein et al., 2005). DDM-mediated senescence is durable, based on the time it takes for resistant clones to emerge (Chao et al., 2011); therefore, it is not surprising that congener B2 also induces senescence, albeit at significantly reduced levels relative to the parent molecule. Despite justifiable concerns about inducing senescence in solid tumors, retention of some CIS activity across a narrow dose range could impart favorable outcome, specifically in terms of longevity of the response, as demonstrated by the sustained effect of B2 after 3 weeks that was superior to taxol. Furthermore, trepidation related to sustained SASP signaling from persistent senescent cells could be allayed by our finding that cisplatin, typically administered sequentially after taxol, is a potent senolytic that can kill senescent cancer cells (Samaraweera et al., 2017).

We are interested in uncovering mechanistic insight at the level of the tubulin-ligand interaction to account for the improved dose-response relationship of B2 relative to DDM or taxol. Clearly, modulation of the lactone and diene confer increased $\mathrm{E}_{\text {Max }}$ and AUC such that cell killing is a more prevalent mechanism of action for congeners A2 and B2. However, this may be due to mechanisms distal to tubulin polymerization, including enhanced cellular uptake and resistance to efflux and/or resistance to metabolic degradation. These attributes will be determined in future mouse studies to evaluate systemic toxicity and in vivo efficacy of these molecules.

Other explanations include mechanisms proximal to the tubulin-ligand interaction, including different binding affinity of B2 compared with DDM or taxol, thereby inducing differential effects on tubulin dimers and/or the microtubule lattice. To address this, we generated a crystal structure of the tubulin-B2 complex to uncover the molecular interaction and demonstrated a shift in the occupation of the lactone of B2 versus DDM in the taxane site. Minor changes were observed at the monoene moiety. Thus, removal of both the C2-methyl and C3-hydroxyl could render B2 more adaptable to changes in the taxane site and provide a molecular basis to account, at least partially, for the improved anticancer activity of B2 versus DDM.

Although the crystallography studies were done using bovine brain tubulin, we are cognizant of the fact that the tubulin family is composed of multiple isotypes, each assumed to possess functional specificity within a given cell type. It is plausible that DDM binds a specific tubulin isotype with a specialized function in G1/S checkpoint integrity or similar, such that perturbation causes potent senescence. Lactone and diene modifications could also influence binding to distinct tubulin isotypes that ultimately modulates cellular fate, i.e., death versus senescence. Although the lactone binding 
domain of human tubulins is largely invariant, there are isotype-defining amino acid changes in the diene-interacting domain that could potentially modulate tubulin-ligand interactions. Delineating such interactions would prove invaluable in guiding future structural refinements of DDM. This requires biochemical testing that presently is challenging for studies of human tubulin, although additional studies are ongoing to address these questions and to provide critical insight into the molecular mechanism of action of $\mathrm{B} 2$, a promising anticancer molecule.

\section{Acknowledgments}

The authors acknowledge the assistance of Dr. Chia-Ping H. Yang in preparing congener stock solutions.

\section{Authorship Contributions}

Participated in research design: Guo, Prota, Steinmetz, Horwitz, Smith, McDaid.

Conducted experiments: Guo, Rodriguez-Gabin (cell-based analysis), Prota (X-ray crystallography), Mühlethaler (protein expression, purification and crystallization), Zhang (chemical synthesis).

Contributed reagents and analytic tools: Ye, Smith.

Performed data analysis: Rodriguez-Gabin, Prota, Ye (biostatistics), Steinmetz (structure analysis), McDaid (cell-based analysis).

Wrote or contributed to the writing of the manuscript: Guo, Rodriguez-Gabin, Proa, Mühlethaler, Zhang, Ye, Steinmetz, Horwitz, Smith, McDaid.

\section{References}

Aoshiba K, Tsuji T, Kameyama S, Itoh M, Semba S, Yamaguchi K, and Nakamura H (2013) Senescence-associated secretory phenotype in a mouse model of bleomycininduced lung injury. Exp Toxicol Pathol 65:1053-1062.

Baker DJ, Wijshake T, Tchkonia T, LeBrasseur NK, Childs BG, van de Sluis B, Kirkland JL, and van Deursen JM (2011) Clearance of p16Ink4a-positive senescent cells delays ageing-associated disorders. Nature 479:232-236.

Batlle E, Sancho E, Francí C, Domínguez D, Monfar M, Baulida J, and García De Herreros A (2000) The transcription factor snail is a repressor of E-cadherin gene expression in epithelial tumour cells. Nat Cell Biol 2:84-89.

Bradley G, Naik M, and Ling V (1989) P-glycoprotein expression in multidrugresistant human ovarian carcinoma cell lines. Cancer Res 49:2790-2796.

Braumüller H, Wieder T, Brenner E, Aßmann S, Hahn M, Alkhaled M, Schilbach K, Essmann F, Kneilling M, Griessinger C, et al. (2013) T-helper-1-cell cytokines drive cancer into senescence. Nature 494:361-365.

Chao SK, Lin J, Brouwer-Visser J, Smith AB III, Horwitz SB, and McDaid HM (2011) Resistance to discodermolide, a microtubule-stabilizing agent and senescence in ducer, is 4E-BP1-dependent. Proc Natl Acad Sci USA 108:391-396.

Childs BG, Durik M, Baker DJ, and van Deursen JM (2015) Cellular senescence in aging and age-related disease: from mechanisms to therapy. Nat Med 21: 1424-1435

Damsky W, Micevic G, Meeth K, Muthusamy V, Curley DP, Santhanakrishnan M, Erdelyi I, Platt JT, Huang L, Theodosakis N, et al (2015) mTORC1 activation blocks BrafV600E-induced growth arrest but is insufficient for melanoma formation. Cancer Cell 27:41-56.

Demaria M, O'Leary MN, Chang J, Shao L, Liu S, Alimirah F, Koenig K, Le C, Mitin N, Deal AM, et al. (2017) Cellular senescence promotes adverse effects of chemotherapy and cancer relapse. Cancer Discov 7:165-176.

Ewald JA, Desotelle JA, Wilding G, and Jarrard DF (2010) Therapy-induced senescence in cancer. J Natl Cancer Inst 102:1536-1546.

Fallahi-Sichani M, Honarnejad S, Heiser LM, Gray JW, and Sorger PK (2013) Metrics other than potency reveal systematic variation in responses to cancer drugs. Nat Chem Biol 9:708-714.

Fan Y, Schreiber EM, and Day BW (2009) Human liver microsomal metabolism of (+)-discodermolide. J Nat Prod 72:1748-1754.

Flach J, Bakker ST, Mohrin M, Conroy PC, Pietras EM, Reynaud D, Alvarez S, Diolaiti ME, Ugarte F, Forsberg EC, et al. (2014) Replication stress is a potent driver of functional decline in ageing haematopoietic stem cells. Nature $\mathbf{5 1 2}$ 198-202.

Gosselin K, Martien S, Pourtier A, Vercamer C, Ostoich P, Morat L, Sabatier L, Duprez L, T'kint de Roodenbeke C, Gilson E, et al. (2009) Senescence-associated oxidative DNA damage promotes the generation of neoplastic cells. Cancer Res 69 : $7917-7925$

Hafner M, Niepel M, Chung M, and Sorger PK (2016) Growth rate inhibition metrics correct for confounders in measuring sensitivity to cancer drugs. Nat Methods 13 521-527.

Itahana K, Campisi J, and Dimri GP (2007) Methods to detect biomarkers of cellular senescence: the senescence-associated beta-galactosidase assay. Methods Mol Biol 371:21-31.

Jones KD (2018) Unclassifiable interstitial lung disease: a pathologist's perspective. Eur Respir Rev 27:170132.
Katsimpardi L, Litterman NK, Schein PA, Miller CM, Loffredo FS, Wojtkiewicz GR, Chen JW, Lee RT, Wagers AJ, and Rubin LL (2014) Vascular and neurogenic rejuvenation of the aging mouse brain by young systemic factors. Science $\mathbf{3 4 4}$ $630-634$

Klein LE, Freeze BS, Smith AB III, and Horwitz SB (2005) The microtubule stabilizing agent discodermolide is a potent inducer of accelerated cell senescence. Cell Cycle 4:501-507.

Knudsen ES and Witkiewicz AK (2017) The strange case of CDK4/6 inhibitors: mechanisms, resistance, and combination strategies. Trends Cancer 3: $39-55$

Laberge R-M, Awad P, Campisi J, and Desprez P-Y (2012) Epithelial-mesenchymal transition induced by senescent fibroblasts. Cancer Microenviron 5:39-44.

Le Duff M, Gouju J, Jonchère B, Guillon J, Toutain B, Boissard A, Henry C, Guette C, Lelièvre E, and Coqueret O (2018) Regulation of senescence escape by the cdk4-EZH2-AP2M1 pathway in response to chemotherapy. Cell Death Dis 9:199.

Lehmann BD, Bauer JA, Chen X, Sanders ME, Chakravarthy AB, Shyr Y, and Pietenpol JA (2011) Identification of human triple-negative breast cancer subtypes and preclinical models for selection of targeted therapies. $J$ Clin Invest 121:2750-2767.

Milanovic M, Fan DNY, Belenki D, Däbritz JHM, Zhao Z, Yu Y, Dörr JR, Dimitrova L, Lenze D, Monteiro Barbosa IA, et al. (2018) Senescence-associated reprogramming promotes cancer stemness. Nature 553:96-100.

Mita A, Lockhart AC, Chen TL, Bochinski J, Curtright J, Cooper W, Hammond L, Rothenberg M, Rowinsky E, and Sharma S (2004) A phase I pharmacokinetic (PK) trial of XAA296A (discodermolide) administered every 3 wks to adult patients with advanced solid malignancies (Abstract). J Clin Oncol 22(Suppl 14): 2025

Morgan WA (1939) Test for the significance of the difference between the two variances IN a sample from a normal bivariate population. Biometrika 31:13-19.

Nadaradjane C, Yang CH, Rodriguez-Gabin A, Ye K, Sugasawa K, Atasoylu O, Smith AB III, Horwitz SB, and McDaid HM (2018) Improved dose-response relationship of (+)-discodermolide-taxol hybrid congeners. J Nat Prod 81:607-615.

Nieto MA, Sargent MG, Wilkinson DG, and Cooke J (1994) Control of cell behavior during vertebrate development by Slug, a zinc finger gene. Science $\mathbf{2 6 4}$ : 835-839.

Ogrunc M, Di Micco R, Liontos M, Bombardelli L, Mione M, Fumagalli M, Gorgoulis VG, and d'Adda di Fagagna F (2014) Oncogene-induced reactive oxygen species fuel hyperproliferation and DNA damage response activation. Cell Death Differ 21: 998-1012.

Olsen LF, Issinger O-G, and Guerra B (2013) The Yin and Yang of redox regulation. Redox Rep 18:245-252.

Prota AE, Bargsten K, Redondo-Horcajo M, Smith AB III, Yang CH, McDaid HM, Paterson I, Horwitz SB, Fernando Díaz J, and Steinmetz MO (2017) Structural basis of microtubule stabilization by discodermolide. ChemBioChem 18: 905-909.

Samaraweera L, Adomako A, Rodriguez-Gabin A, and McDaid HM (2017) A novel indication for panobinostat as a senolytic drug in NSCLC and HNSCC. Sci Rep 7: 1900

Samaraweera L, Liu L, Suzuki M, Horwitz SB, and McDaid HM (2012) Senescence reversion contributes to acquired drug resistance (Abstract). Cancer Res 72 (Suppl 1):4230.

Sampah MES, Shen L, Jilek BL, and Siliciano RF (2011) Dose-response curve slope is a missing dimension in the analysis of HIV-1 drug resistance. Proc Natl Acad Sci USA 108:7613-7618.

Santaguida S, Richardson A, Iyer DR, M'Saad O, Zasadil L, Knouse KA, Wong YL Rhind N, Desai A, and Amon A (2017) Chromosome mis-segregation generates cellcycle-arrested cells with complex karyotypes that are eliminated by the immune system. Dev Cell 41:638-651.e5.

Schafer MJ, White TA, Iijima K, Haak AJ, Ligresti G, Atkinson EJ, Oberg AL, Birch J, Salmonowicz H, Zhu Y, et al. (2017) Cellular senescence mediates fibrotic pulmonary disease. Nat Commun 8:14532.

Segu VBG, Li G, and Metz SA (1998) Use of a soluble tetrazolium compound to assay metabolic activation of intact beta cells. Metabolism 47:824-830.

Sharpless NE and Sherr CJ (2015) Forging a signature of in vivo senescence. Nat Rev Cancer 15:397-408.

Shaw SJ (2008) The structure activity relationship of discodermolide analogues. Mini Rev Med Chem 8:276-284.

Shaw SJ, Sundermann KF, Burlingame MA, Myles DC, Freeze BS, Xian M, Brouard I, and Smith AB III (2005) Toward understanding how the lactone moiety of discodermolide affects activity. $J$ Am Chem Soc 127:6532-6533.

Shaw SJ, Sundermann KF, Burlingame MA, Zhang D, Petryka J, and Myles DC (2006) A series of 23,24-dihydrodiscodermolide analogues with simplified lactone regions. Bioorg Med Chem Lett 16:1961-1964.

Skehan P, Storeng R, Scudiero D, Monks A, McMahon J, Vistica D, Warren JT, Bokesch H, Kenney S, and Boyd MR (1990) New colorimetric cytotoxicity assay for anticancer-drug screening. J Natl Cancer Inst 82:1107-1112.

Smith AB, Beauchamp TJ, LaMarche MJ, Kaufman MD, Qiu Y, Arimoto H, Jones DR, and Kobayashi K (2000) Evolution of a gram-scale synthesis of (+)-discodermolide. $J$ Am Chem Soc 122:8654-8664.

Smith AB and Freeze BS (2007) (+)-Discodermolide: total synthesis, construction of novel analogues, and biological evaluation. Tetrahedron 64:261-298.

Smith AB III, Kaufman MD, Beauchamp TJ, LaMarche MJ, and Arimoto H (1999) Gram-scale synthesis of (+)-discodermolide. Org Lett 1:1823-1826.

Smith AB III, Rucker PV, Brouard I, Freeze BS, Xia S, and Horwitz SB (2005) Design, synthesis, and biological evaluation of potent discodermolide fluorescent and photoaffinity molecular probes. Org Lett 7:5199-5202.

Smith AB, Sugasawa K, Atasoylu O, Yang CP, and Horwitz SB (2011) Design and synthesis of (+)-discodermolide-paclitaxel hybrids leading to enhanced biological activity. J Med Chem 54:6319-6327. 
Smith AB III and Xian M (2005) Design, synthesis, and biological evaluation of simplified analogues of (+)-discodermolide. Additional insights on the importance of the diene, the C7 hydroxyl, and the lactone. Org Lett 7:5229-5232.

Storer M, Mas A, Robert-Moreno A, Pecoraro M, Ortells MC, Di Giacomo V, Yosef R, Pilpel N, Krizhanovsky V, Sharpe J, et al. (2013) Senescence is a developmental mechanism that contributes to embryonic growth and patterning. Cell 155: $1119-1130$.

Watson EV and Elledge SJ (2017) Aneuploidy police detect chromosomal imbalance triggering immune crackdown!. Trends Genet 33:662-664.

Wolff AC (2016) CDK4 and CDK6 inhibition in breast cancer - a new standard $N$ Engl J Med 375:1993-1994.
Yang CH, Wang C, Ojima I, and Horwitz SB (2018) Taxol analogues exhibit differential effects on photoaffinity labeling of $\beta$-tubulin and the multidrug resistance associated P-glycoprotein. J Nat Prod 81:600-606.

Ziegler DV, Wiley CD, and Velarde MC (2015) Mitochondrial effectors of cellular senescence: beyond the free radical theory of aging. Aging Cell 14:1-7.

Address correspondence to: Dr. Hayley M. McDaid, Department of Molecular Pharmacology, Albert Einstein College of Medicine, 1300 Morris Pk Ave, F249b, Bronx, NY 10461. E-mail: hayley.mcdaid@einsteinmed.org 